\title{
Cultura y lenguaje *
}

\author{
FERNANDO SALMERÓN
}

Al Profesor José Luis Aranguren

Hace dos años me fue concedido el honor de decir algunas palabras al iniciarse el I Simposio Hispano-Mexicano de Filosofia en la Universidad de Salamanca, restringido en aquella ocasión a cuestiones de lógica, filosofía de la ciencia y del lenguaje. El año pasado asistí como invitado al I Encuentro Hispano-Mexicano de Filosofia moral y politica, que tuvo lugar en Santander, patrocinado por la Universidad Menéndez y Pelayo. Ahora se me ha pedido pronunciar estas palabras en la clausura del II Encuentro Hispano-Mexicano. Debo decir que la satisfacción que he sentido por tales reiteradas muestras de amistad y benevolencia por parte de los diversos responsables de la organización de estos actos no logra ocultarme la dificultad de hallar una explicación —por encima de esos motivos que tanto agradezco- para semejantes coincidencias.

La reunión iniciada en el Pazo de Mariñán, que hoy se clausura en este Instituto de Cooperación Iberoamericana, con haber dedicado la mayor parte de su tiempo al estudio de problemas de filosofía moral y política, ha cubierto

* El texto de F. Salmerón (Córdoba, Veracruz, 1925-México, D. F., 1997) constituyó la Conferencia de Clausura del II Encuentro Hispano-Mexicano de Filosofia Moral y Política de 1986 - cuyas Actas editaron J. A. Gimbernat y I. M. González, Instituto de Filosofia del CSIC, Madrid, 1988 - y ha sido recientemente recogido en el volumen póstumo Diversidad cultural y tolerancia, México-Buenos Aires-Barcelona, 1988, pp. 87-102, con un prólogo de León Olivé del que entresacamos este párrafo: «En dicha conferencia, Salmerón desarrolla una ingeniosa idea con la que da cuenta de un proyecto filosófico común, de pensamiento y de cultura, que agrupa a los países de lengua española. Defiende en ella nuevamente y de manera vigorosa las ideas que compartió con su maestro José Gaos y que en gran medida se han ido realizando gracias a sus esfuerzos: mayor comunicación entre las comunidades de pensamiento en los paises hispanohablantes; la necesidad de atender a nuestras tradiciones culturales y a sus clásicos en materia de historia de las ideas; la importancia de hacer valer la propia lengua en la conunicación filosófica internacional, toda vez que esa lengua forma parte de la tradición de pensamiento y de la cultura a la que uno pertenece. Además, Salmerón aboga por algunas cuestiones de orden práctico que habian sido también el sueño de Gaos, como la realización de un gran Congreso que convocara a todos los pensadores del mundo iberoamericano* (pp. 9-25, p. 20). 
también, al menos durante cuatro sesiones, cuestiones relativas a la situación de la filosofia en países de lengua castellana - sin que faltaran las oportunidades de transitar de un grupo de problemas a otro-. Y nada más natural dadas las características de quicnes hemos asistido: principalmente españoles y mexicanos, pero también invitados originarios de otros países donde el castellano es la lengua dominante, cuando no la única. Con una sola excepción que confirma la regla.

El tema de estas palabras de clausura parece obligado por esta circunstancia: nos separan fronteras nacionales marcadas por estructuras de poder político; en cambio, nos acerca la unidad de la lengua en que casi todos hemos sido educados, al lado de otras experiencias históricas comunes. Tal circunstancia podría ser de interés en una reunión de filósofos, al menos por dos razones: una, relacionada con experiencias históricas recientes; la otra, con desarrollos contemporáneos de la filosofía en el pasado inmediato.

\section{II}

Para reducir el asunto solamente al caso de México, en razón de poder acudir a algún ejemplo de detalle, quisiera recordar experiencias recientes de migración intelectual por motivos de violencia política. Las crisis internas de nuestros países desembocan a veces en conflictos o en francas guerras civiles - a las que no siempre son ajenos los imperios, deseosos de rectificar fronteras o simplemente de aumentar impuestos-. Por supuesto que el exilio político no es un fenómeno específico de nuestro tiempo, pero no cabe duda que en este siglo ha alcanzado proporciones que antes no tuvo. La revolución mexicana de 1910 hizo salir del país a varios de los protagonistas de la historia de las ideas en ese período de México: Justo Sierra murió en el destierro; Vasconcelos salió varias veces; el dominicano Pedro Enríquez Ureña se ausentó en esos años para establecer su residencia definitiva en Argentina; Alfonso Reyes pasó años de destierro en Madrid y algunas de sus más bellas páginas son páginas de exilio. Después prolongó su ausencia de México en el servicio diplomático y vivió en París, pero sobre todo en Montevideo, Buenos Aires y Río.

Entre otras enseñanzas, Reyes nos dejó una ciertamente invaluable: la convicción de que somos herederos de todas las culturas de Occidente. Las generaciones posteriores que aprendieron esa lección europea e iberoamericana ampliaron aún más esa convicción en un sentido cosmopolita y de rescate de nuestro pasado prehispánico. Pero el poema que Jorge Luis Borges escribió a la mucrte de Reyes subraya un rasgo de aquella universalidad que acentúa su relación con la lengua castellana, desde la prosa del Mio Cid «hasta los arrabales del lunfardo». Y sólo por este rasgo se comprende que Borges pudiera decir de su amigo mexicano que: 


\begin{abstract}
«Supo bien aquel arte que ninguno supo del todo, ni Simbad ni Ulises, que es pasar de un país a otros países y estar integramente en cada uno.»
\end{abstract}

A partir de los últimos años de la década de 1930, en México hemos vivido una situación diferente: recibimos primero a los refugiados que salieron de España a la caída de la República; después, a grupos diversos de centroamcricanos; finalmente, a argentinos, uruguayos y de otros países de América del Sur. Con independencia del significado que ha tenido la presencia de estos grupos para el desarrollo de las ideas filosóficas en México, permanece el valor de la experiencia integradora. Ellos y nosotros descubrimos en este tiempo muchos puntos de semejanza en nuestras respectivas situaciones culturales, correspondencias notables en la marcha de las ideas en nuestros países, y todo dentro de una comunidad de tradición que parece coincidir completamente con las fronteras imprecisas de la geografía de la lengua castellana y, en general, de las lenguas originarias de esta península.

Entre quienes llegaron a México con motivo de la guerra civil española tal vez nadie reflexionó sobre estas materias tanto como José Gaos, ante todo en los años inmediatamente anteriores a 1945. Pocos estaban como él tan vocados para csa tarea. Al iniciar sus estudios de filosofía en Madrid, Gaos había tenido dudas para elegir entre esta disciplina y la filología; tal era su inclinación para el estudio de las lenguas. Más tarde, por sugerencia de su maestro Ortega, había aprendido el árabe, con vistas a un proyecto nunca realizado de historia de la filosofía en España - que en esas fechas dio como único fruto el breve texto sobre Maimónides-. Para su trabajo con los libros alemanes clásicos y contemporáneos Gaos había tenido el consejo cercano de Morente y Zubiri, y para su estudio de la filosofía escolástica el de su joven discípulo Manuel Mindán. La sensibilidad de Gaos para cuestiones lingüísticas quedó probada de muchas maneras, entre otras con sus traducciones; pero también con sus propuestas de modificar palabras castellanas para describir su adaptación al país que vino a ser su patria de destino: hablaba del momento de su «empatriación» en México; y para rechazar la situación de desterrado decía - con un término que hizo fortuna- que él y sus colegas habian sido «transterrados».

A fines de 1938, fecha de su llegada a México, Gaos sintió la necesidad de revivir aquel proyecto orteguiano de historia de la filosofía en España y de ampliarlo en dos dirccciones. En primer lugar, como una historia del pensamiento, no de la filosofía en sentido estricto -porque Gaos hacía en este punto distinciones muy precisas--. Y la palabra «pensamiento» alcanzaba scgún él, en su amplitud, a la filosofía en scntido estricto, pero tambićn a las ideas expuestas con métodos científicos o expresadas en la literatura a propósito de problemas de circunstancias. En segundo lugar, el proyecto se extendió hasta cubrir no sólo la historia de las ideas en España, sino en todos los países 
de lengua española. $\mathrm{Y}$ aunque el título del seminario que Gaos fundó en la recién creada Casa de España en México quedaba limitado por estos términos, de hecho se hicieron allí investigaciones también sobre Brasil y Portugal.

Varios de los ensayos publicados por Gaos entre 1940 y 1945 tienen el carácter de hipótesis de trabajo para aquella historia proyectada. En ellos se traza una propuesta de periodización, pero además una caracterización e interpretación de la historia del pensamiento hispanoamericano como una unidad, así como su localización dentro de la más vasta historia de las ideas, que a su vez se integra en la historia universal. De tales planteamientos habría muchos aspectos que recordar ahora como materia de interés para la reunión que concluye. Me limitaré a citar solamente uno, sin tocar siquiera las correspondencias entre la historia del pensamiento en España y la del pensamiento en México, ni los nexos individuales entre filosofos de los dos países que Gaos registra en un ensayo sobre El pensamiento hispanoamericano. Pero este aspecto nos conduce al tema de la unidad de la lengua y de su relación con el pensamiento, que como dije antes podría ser una segunda razón para destacar la importancia de una reunión como la nuestra en vista de los desarrollos contemporáneos de la filosofía.

\section{III}

El texto de Gaos a que he hecho alusión es una ponencia de 1944 presentada para su discusión en el Centro de Estudios Sociales del Colegio de México. En un apartado destinado a definiciones y supuestos la ponencia establece como un hecho fuera de toda duda la existencia de diversas configuraciones sociales, entre las cuales se dan las agrupaciones nacionales; pero, además, afirma la contribución del pensamiento y el lenguaje a la formación de las nacionalidades. Y deja sin aclarar otro punto, que se conecta con el estilo del pensamiento:

«Entre fondo y forma - nos dice subrayando el "entre"-, por la vinculación mutua del pensamiento y ella, está una forma singularmente importante: la lengua.» Hasta aquí la cita.

La relación entre pensamiento, lenguaje y comunidad nacional permanece, por tanto, afirmada pero indiscutida, aunque se reconoce expresamente su importancia. Y neutralizada por la tesis central que la ponencia defiende: la tesis de la unidad de un pensamiento y hasta de correspondencias en los desarrollos filosóficos paralelos, que se comprenden en función de una comunidad lingüística supranacional y no en función de otros rasgos de las agrupaciones nacionales.

La publicación recoge los comentarios de algunos asistentes a la reunión, filósofos, historiadores y literatos $-\mathrm{y}$ de un antropólogo: Alfonso Caso-. A partir de la intervención de este último -en cuyas palabras se perciben las posiciones del relativismo cultural-- la discusión deriva hacia las diferencias 
entre la concepción del mundo europea y la hispanoamericana, para insistir en lo específico de esta última y señalar que tal cosa se debe a sus elementos aborígenes.

Al responder a los comentarios el ponente no niega - como cuestión de principio- la posibilidad de que existan ingredientes aborígenes dentro del pensamiento hispanoamericano. Lo que niega, en cambio, de manera muy enfática, es lo siguiente: que existan métodos para discernirlo y denunciarlo, o que pucda ser percibido sin ayuda de método alguno. «Porque, a priori, no me parece posible que lo aborigen no se traduzca realmente en pensamiento.» $\mathrm{Y}$ de esta manera -habrá que completar el argumento de Gaos- que permanezca francamente indiscernible dentro del cuerpo general de las ideas, salvo por los matices que puedan descubrirse en la circunstancia inmediata que dio origen a los planteamientos.

Las tesis fundamentales del relativismo cultural habían sido introducidas en México desde principios de siglo - a partir de 1911 para ser exactos-, con la estancia de Franz Boas como profesor de antropología en la Escuela de Altos Estudios. Boas insistió, apoyado en observaciones de su trabajo de campo, en que lenguaje y cultura no tienen necesariamente el mismo destino: de modo que una lengua puede permanecer constante aunque cambie la cultura; como puede también suceder lo contrario, que la cultura permanezca y cambie la lengua. Esto permite conjeturar la ausencia de una relación directa entre la cultura de un grupo y el lenguaje que habla este grupo. Y, desde luego, permite rechazar la tesis de que un cierto estado de cultura esté condicionado por rasgos morfológicos del lenguaje. La relación, sin embargo, puede darse en un sentido inverso: en el sentido de que, en alguna medida, la forma del lenguaje puede ser moldeada por el estado de la cultura. $Y$ esta medida, que habria que puntualizar en cada cáso mediante la observación, será siempre de importancia menor y no podrá constituir un obstáculo para que un pueblo avance hacia formas más complejas de pensamiento.

Lo que hay que explicar, nos dice Boas, son las influencias que orientan los esfuerzos del hombre para entender los fenómenos de la naturaleza, los prejuicios con que clasifica sus experiencias, las ideas tradicionales o las hipótesis no examinadas a partir de las cuales interpreta cada nueva percepción. Pero todo esto -mitología, teología y categorías filosóficas-, que está en el fundamento de nuestros raciocinios, supone un elemento que se transmite por la educación a los nuevos miembros de cada comunidad como sustancia tradicional, casi lo mismo que el folclore. Aquí se dan las diferencias entre las culturas que trata de establecer el antropólogo, y no en supuestas peculiaridades de la mente del hombre. La ventaja que ofrece la lingǘstica en estos estudios comparativos es que el proceso que conduce a la formación de estas categorías puede seguirse en las variaciones del lenguaje, sin los factores engañosos y perturbadores que son tan comunes en la etnología. Pero salvo esta función instrumental, la lingüística tiene que aceptar el hecho de la falta de relación directa entre la cultura de un grupo y su lenguaje. 


\section{IV}

Hasta aquí lo que podríamos llamar el núcleo del relativismo cultural de Boas, que, no sín polémica, sobrevivió entre los antropólogos mexicanos hasta comienzos de la década de los años cuarenta - justo en las fechas de la publicación de Gaos-. Por estos años, otros desarrollos vinieron a constituir la base doctrinal de la política indigenista del gobierno mexicano, que propugnó por el uso de las lenguas vernáculas en la enseñanza. Los desarrollos no venían exclusivamente de la linguística, sino de la política: por ejemplo, de las tesis oficiales del marxismo acerca de las nacionalidades. Aunque también venían de la lingüística.

Las ideas de Boas fueron prolongadas en una dirección que él mismo no había previsto. Nunca puso en duda algunas tesis sobre pensamiento y lenguaje ahora inaceptables; por ejemplo: que siempre que pensamos, pensamos en palabras, y éstas, por tanto, permanecen asociadas de manera inconsciente a aquellos agrupamientos tradicionales de ideas que utilizamos como hipótesis no examinadas de nuestras percepciones y conocimientos. Pero no parece haber ido más allá de esto.

En el tema de las relaciones entre lenguaje y cultura Edward Sapir siguió a Boas, de una manera casi literal, en sus primeras publicaciones. Pero a partir del comienzo de la década de los años treinta sus trabajos sobre las realidades psicológicas del lenguaje lo llevaron a establecer una tesis que contradice a Boas, en el sentido de que al menos ciertas percepciones resultan constreñidas por los supuestos de las estructuras lingüísticas del sujeto que habla. Si el lenguaje no determina los contenidos de la percepción, al menos los condiciona con sus prácticas de categorización y predispone al hablante a ciertas opciones de interpretación. Un punto de vista que, al cuestionar la neutralidad del lenguaje, hizo posible reducir el relativismo cultural a uno puramente lingüístico y asociar, en términos generales, una lengua a una cultura, a una nación o a una concepción del mundo. Lo que permitió recuperar la orientación iniciada por Herder y Humboldt, que siempre mantuvo cierto vigor en el pensamiento alemán.

El encargado de llevar estos planteamientos a sus consecuencias extremas fue Benjamin Lee Whorf, un discipulo de Sapir.

Whorf había estado en México en 1930, dedicado al estudio de dialectos del náhuatl de una zona cercana a la ciudad capital; estudios que aún aprecian los antropólogos mexicanos por sus méritos lingüísticos. Más tarde, asociado con el grupo de discípulos de Sapir, Whorf publica sus ensayos propiamente filosóficos sobre mente, lenguaje y realidad. Pero además intenta la prueba empírica de sus hipótesis en el estudio de la lengua de un grupo indígena de Arizona y su posterior descripción etnográfica. Según sus conclusiones, un acuerdo mantenido por la comunidad divide a la naturaleza en porciones y la organiza en conceptos codificados que siguen los modelos del lenguaje, 
de modo que no es posible hablar sin adscribirse a esa organización y clasificación. De esta manera, el sistema lingüístico de cada lengua particular es el formador de las ideas acerca de la realidad y el verdadero guía de los procesos mentales individuales.

El trabajo profesional de Whorf como lingüista convenció a los antropólogos mexicanos - también sus ideas generales sobre pensamiento y lenguaje-. Porque quienes llevaron a cabo la reforma política en relación con la enseñanza de las lenguas vernáculas que se implantó en 1944 reclamaban los nombres de Sapir y Whorf entre los respaldos teóricos de su propuesta. Respaldos presentes también en alguna de las publicaciones mexicanas de aquella época, en que los trabajos etnográficos sobre una población indígena se integran con la investigación de la percepción cromática del grupo en relación con el lenguajc.

El trabajo de Whorf como filósofo del lenguaje parece haber sido menos convincente, sobre todo entre los filósofos. Dicho en términos muy generales, la filosofía contemporánea difiere de algunos de los supuestos de Whorf sobre la naturaleza del lenguaje. Asunto que no vamos a tocar aquí. Pero me gustaría decir dos palabras sobre la orientación de los principales argumentos que se han esgrimido en contra de sus hipótesis específicas y de sus procedimientos de corroboración.

Probablemente algunos filósofos estarían de acuerdo en defender, con los matices pertinentes, alguna forma de absolutismo que remita a leyes universales de la razón; pero seguramente serían muy pocos los que estuvieran interesados en rechazar un relativismo cultural presentado, por ejemplo, en los términos de Franz Boas. Incluso, tal vez, no faltaría acuerdo para aceptar que una lengua puede constituirse, en un momento dado, en obstáculo para la expresión de ideas, porque de alguna manera la actividad lingüística encuentra su lugar cn la experiencia vivida de una cultura o, si se quiere, de una forma de vida. Pero más allá de las limitaciones que provienen de la pobreza de un vocabulario disponible, o de supuestos dudosos encerrados en expresiones corrientes, las influencias más generales que la estructura particular de una lengua ejerce sobre el pensamiento son más difíciles de precisar.

Los antropólogos pueden, en el estudio de una comunidad, identificar los términos claves de una concepción del mundo más o menos comparable a otras. Seguramente pueden también establecer correspondencias entre los términos de aquella concepción del mundo y algunos rasgos gramaticales especialmente elegidos. Pero hasta ahora no han podido ofrecer criterios estrictos para decidir que un determinado vocablo de alcance filosófico haya surgido como tal precisamente a partir de un rasgo de la lengua estudiada. $\mathrm{Y}$ en la medida en que estos criterios de método no sean esclarecidos, sus hallazgos pueden resultar atractivos y sugerentes, pero no habrá manera de comprobar su valor de verdad.

Por otra parte, si es cierto que la variedad de las lenguas - como la variedad de las culturas - es un hecho impresionante que invita a imaginar también 
una variedad de concepciones del mundo inconmensurables, no es menos cierto que las lenguas cambian constantemente y que las que viven en contacto se acercan unas a otras para afinar sus posibilidades de traducción, fundadas ante todo en la universalidad de las propias lenguas.

La filosofía de los tiempos modernos, una vez que hubo abandonado el latín, nos ha dejado pruebas más que suficientes acerca de la precisión con que los sistemas filosóficos se expresan con igual facilidad en distintas lenguas y así pueden participar en el mismo juego de la discusión filosófica. $Y$ de tal manera nos hemos habituado a esto, que de modo inconsciente aplicamos a diario el dicho del poeta - cambiando los términos, naturalmente- para definir el discurso filosófico como aquello que permanece una vez que hemos hecho la traducción. Y aún con mayor firmeza, porque bien pudiera ser que lo dicho para la filosofía no valga igual para la creación literaria.

Pero el punto sobre el que ahora quisiera llamar la atención es el siguiente: las dos orientaciones fundamentales de los argumentos contra la tesis de Whorf que acabo de resumir - una que utiliza la traducción como contraejemplo y otra que se refiere a los métodos de investigación para discernir los orígenes lingüísticos de las categorías filosóficas - están contenidas en la breve respuesta de Gaos a Alfonso Caso en 1944.

Aquel diálogo entre el antropólogo mexicano y el filósofo transterrado, sin embargo, no excluye acuerdos — también para nosotros admisibles-. Hace ya tiempo que las preocupaciones filosóficas por el estudio del lenguaje no se concentran en las meras relaciorres sintácticas entre los signos; ni siquiera en las relaciones semánticas y en las cuestiones acerca del significado, sino que incluso parece haber pasado a un primer plano de atención cl estudio de las relaciones pragmáticas: esto es, las que se dan entre los signos y los usuarios, y entre ambos y su contexto. El punto de vista pragmático que sc ocupa del lenguaje como un comportamiento, como un modo de actuar de los seres humanos, está menos alejado de disciplinas como la antropología, puesto que pretende tomar en cuenta las circunstancias que concurren en la práctica de una comunidad lingüística. $\mathrm{Y}$ en estas materias, algunas de las tesis relativistas, que no parecen apuntar tanto a diferencias en la mentalidad de los hombres de diversas culturas ni a ideas innatas, sino más bien a ciertas uniformidades empíricas de la vida social y a necesidades históricas de la comunicación humana, podrían probablemente ser llevadas a terrenos más firmes, aunque más modestos. Con tal que no se pierda de vista que en estos terrenos no se pueden apoyar las soluciones a los problemas epistemológicos fundamentales.

Whorf mismo, vale la pena recordarlo, en un artículo de 1940 titulado "Linguistics as an exact science", con la imprecisión de sus afirmaciones gene- 
rales y metafóricas, decía del conocimiento científico lo siguiente: $\kappa_{\ldots .}$ La concepción del mundo de la ciencia moderna surge de la alta especialización de la gramática básica de las lenguas occidentales indo-europeas. Pero, por supuesto, la ciencia no es causada por la gramática; simplemente es coloreada por ella».

La distinción de Gaos, que deja a salvo de todo relativismo a la filosofia en sentido estricto, advierte que el pensamiento - definido como respuesta a la urgencia de los problemas inmediatos en formas de expresión no filosóficasqueda marcado por la circunstancia que está en el origen de sus planteamientos. Pero el saber que este contexto es inevitable de ninguna manera es garantía de verdad; es simplemente la marca de la autenticidad.

Las propuestas finales de la ponencia de Gaos de que hemos hablado no son propuestas filosóficas, tampoco son lingüísticas ni siquiera en el sentido de la pragmática, sino de cooperación y política culturales: sobre la comunicación entre quienes se dedican a la filosofía en nuestros países; sobre la circulación de sus publicaciones; sobre la necesaria atención a las tradiciones culturales que nos son propias y a sus clásicos en materia de historia de las ideas; sobre la necesidad de hacer valer la propia lengua en la comunidad filosófica internacional y de ganar audiencia a partir de ella para todo lo anterior: tradición, publicaciones y actividad filosófica. Pero, antes que nada, la propuesta de convocar un gran Congreso de filosofía hispanoamericana que prepararía y daría impulso a lo ya dicho.

No insistiré cn estas propuestas. Han sido renovadas con buenos argumentos hace una semana. Pero he querido enlazar el recuerdo reciente de Mariñán con el texto de hace cuarenta años, rodeado de su contexto histórico y de experiencia de vida, porque creo que-estas circunstancias son las que realmente explican la coincidencia en las prcocupaciones prácticas. Las propuestas de Gaos no se fundan en el relativismo cultural, discutido con argumentos pertinentes y dentro de la más rigurosa actualidad de la investigación lingüística de aquellos años. También en Mariñan se habló del relativismo, esta vez a propósito de la sociología del conocimiento, aunque el tema estuvo presente además en una buena parte de las reuniones de filosofía moral de las dos semanas. Y también fue discutido con rigor a partir de la información más actual. Pero las propuestas de orden práctico que parecieron recibir consenso no se presentaron en ningún momento ligadas a tesis alguna del relativismo lingüístico.

La experiencia integradora que los mexicanos vivimos con los transterrados españoles en México, y la que hemos vivido en los años recientes quienes hemos tenido oportunidad de observar en los peninsulares un afán creciente por recuperar como propios los frutos que dejaron en América aquellos transterrados, son simplemente hechos que descubren la existencia de una comunidad de intereses intelectuales que está por encima de las fronteras nacionales. Por supuesto, de una comunidad que se apoya sobre varios siglos de historia y 
cuyas tradiciones culturales - una de las cuales es la lengua- son en gran medida comunes. De una comunidad que está dispuesta, además, a compartir proyectos de futuro.

La lengua en que hemos discutido estas dos semanas, ciudadanos de cinco o seis naciones diferentes, no es simplemente un sistema aislado de signos que todos comprendemos, sino la porción de un conjunto mayor de experiencias históricas comunes en que nos movemos con familiaridad. Muchas cosas aprendemos al aprender la lengua - aunque no sean parte de la lengua ni tengan origen en su gramática.

Al hablar de filosofía, de sociología o de política no ha faltado nunca ese trasfondo cultural compartido, si bien la discreción excesiva o la modestia han preferido negarse a participar en el diálogo de cuestiones domésticas.

\section{VI}

He tratado de recoger algunas de las preocupaciones surgidas en la semana de Mariñán y en la de Madrid -imposible hacerlo con todas y difícil intentarlo con la mayor parte de aquellas que tuvieron un carácter muy técnico-. Pero el relato quedaría incompleto sin una alusión a la conferencia del Profesor Aranguren que clausuró la semana de Mariñán: mientras sus últimas palabras evocaban una imagen de Hegel - la del búho de Minerva que levanta su vuelo a la caída de la tarde-, una rosa roja pasó de mano en mano desde el fondo de la sala hasta llegar a las del profesor y un aplauso cerró el acto en medio de una gran alegría.

Una manera de unirme ahora a ese homenaje al Profesor Aranguren es recordar otras palabras de Hegel que tal vez otros de los presentes recordaron, como yo, aquella tarde de Marinán. Son de un pasaje muy cercano, casi en la misma página del mismo prefacio de la Filosofia del Derecho. Asociación tal vez provocada por la cercanía del texto, o por el scntido del acto, o por la imagen de la rosa, o por el entusiasmo del grupo.

Hegel escribió esas páginas con el entusiasmo de la seguridad de quien ha dejado atrás el tratamiento abstracto de su asunto para describirlo realmente tal como éste es en verdad. Y quiere transmitir esa seguridad repitiendo un viejo adagio griego al que añade además la traducción latina, probablemente la de Erasmo:

Hic Rhodus, hic saltus.

Concebir lo que es real es la tarea de la filosofía, que ha de desentenderse de las construcciones de la imaginación. Por eso mismo puede firmar el filósofo en su prefacio que, en lo que concierne al individuo, cada uno es hijo de su tiempo y sabe que no puede saltar más allá de este tiempo. Como la teoría no puede ir más allá de la realidad misma. Al contraponer abstracción y realidad, 
Hegel da un primer sentido al adagio, que es como la marca de la autenticidad de la filosofía.

Pero ésta no parece haber sido, según algún comentarista -el Profesor T. M. Knox-, la interpretación corriente en los manuales de latín de los tiempos de Hegel. El proverbio se aplicaba más bien a quienes, siempre dispuestos a relatar sus hazañas de lugares lejanos, no lo estaban para dar prueba efectiva de sus habilidades; de esta manera se exigía que las mostraran. Aqui es Rodas $y$ aqui hay que saltar, aplicado a la filosofia, parece una exigencia de objetividad: no basta el convencimiento privado de una opinión, hace falta el control de validez intersubjetiva.

Hegel no toma en cuenta esta segunda interpretación avalada por Erasmo. A cambio, yo no tocaré otras posibles que dan a su imagen final un sentido religioso. Pero sí recordaré una tercera que propone Hegel, jugando con las palabras para cambiar el texto del adagio. La palabra griega para Rodas puede significar también una rosa, y el verbo saltar en latín vale también como el imperativo de danzar. La tarea de un filósofo como Hegel, que tiene de su lado a la razón, es encontrar la alegría en la realidad presente que describe: la filosofia puede danzar en este mundo real sin necesidad de posponer la alegría para una futura construcción imaginaria:

\section{Hier ist die Rose, hier tanze}

Aquí está la rosa, aquí hay que danzar.

Las tres interpretaciones presentadas del adagio griego parecen pertinentes ahora y nos permiten un resumen final de nuestra reunión. Ella misma ha sido una experiencia de comunicación en que señalamos nuestras coincidencias y nuestras diferencias filosóficas, y a la vez de participación en una comunidad con intereses intelectuales cercanos, tradiciones compartidas y proyectos de futuro.

Aquellos que, sin dejar de ser nacionales, no queremos ser nacionalistas, pero que tampoco nos hacemos ilusiones respecto de los imperios y no esperamos en poco tiempo una vida intelectual planetaria, sentimos bajo los pies la tierra sólida cuando nos afirmamos sobre las culturas nacionales de los países que comparten las lenguas que han nacido en la Península Ibérica. Esto es para nosotros la isla de Rodas.

Pero no olvidamos la segunda interpretación del adagio que Hegel desechó. Sabemos que no seria bastante relatar nuestras hazañas filosóficas entre nosotros mismos, sino que tenemos que dar prueba efectiva de nuestras habilidades en la comunidad filosófica internacional y dominar sus reglas de juego. Contamos con nuestras tradiciones, pero también estudiamos las ajenas y seguimos paso a paso sus vicisitudes cuando discuten problemas vivos, lo que ha sido una de las enseñanzas más gratas de csta reunión. La nota de autenticidad y realidad es inseparable de la exigencia de objetividad.

Empezamos a vencer un obstáculo que no es menor que la ausencia de reconocimiento internacional: el obstáculo de la falta de comunicación entre 
nosotros mismos. La experiencia de las reuniones recientes - Salamanca, Santander, Mariñán y Madrid- permite que pensemos en la tercera lectura del adagio griego con los cambios que Hegel sugería. Cambios que añaden la alegría de una comunidad filosófica que empieza a integrar su propio diálogo para participar, desde él, en el diálogo internacional:

Aquí está la rosa, aquí hay que danzar. 